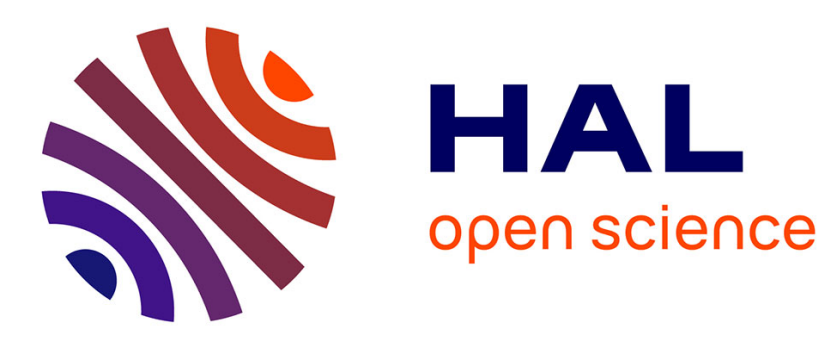

\title{
Full-field evaluation of the onset of microplasticity in a steel specimen
}

\author{
Raphaël Moulart, René Rotinat, Fabrice Pierron
}

\section{To cite this version:}

Raphaël Moulart, René Rotinat, Fabrice Pierron. Full-field evaluation of the onset of microplasticity in a steel specimen. Mechanics of Materials, 2009, 41, pp.1207-1222. hal-00915636v2

\section{HAL Id: hal-00915636 \\ https://hal.science/hal-00915636v2}

Submitted on 30 Sep 2014

HAL is a multi-disciplinary open access archive for the deposit and dissemination of scientific research documents, whether they are published or not. The documents may come from teaching and research institutions in France or abroad, or from public or private research centers.
L'archive ouverte pluridisciplinaire HAL, est destinée au dépôt et à la diffusion de documents scientifiques de niveau recherche, publiés ou non, émanant des établissements d'enseignement et de recherche français ou étrangers, des laboratoires publics ou privés. 


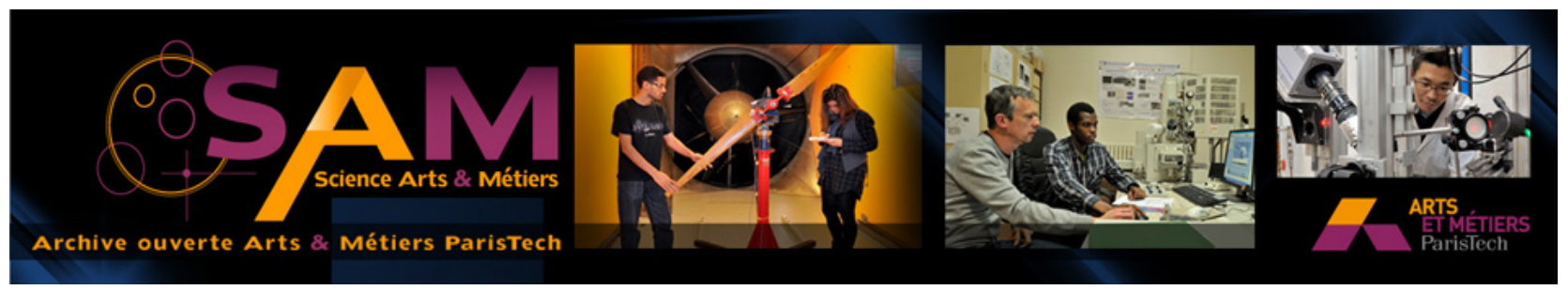

Science Arts \& Métiers (SAM)

is an open access repository that collects the work of Arts et Métiers ParisTech researchers and makes it freely available over the web where possible.

This is an author-deposited version published in: http://sam.ensam.eu

Handle ID: .http://hdl.handle.net/10985/7622

\section{To cite this version :}

Raphaël MOULART, René ROTINAT, Fabrice PIERRON - Full-field evaluation of the onset of microplasticity in a steel specimen - Mechanics of Materials - Vol. 41, p.1207-1222 - 2009 


\title{
Full-field evaluation of the onset of microplasticity in a steel specimen
}

\author{
Raphaël Moulart ${ }^{1, *}$, René Rotinat $^{\mathrm{a}}$, Fabrice Pierron $^{\mathrm{a}}$ \\ ${ }^{a}$ Laboratoire de Mécanique et Procédés de Fabrication (EA 4106), Ecole Nationale Supérieure d'Arts et Métiers, rue Saint-Dominique, B.P. 508, \\ 51006 Châlons-en-Champagne CEDEX, France
}

\begin{abstract}
This work deals with the study of the local onset of microplasticity in a steel specimen under tensile test through the use of a full-field strain measurement method at the micrometric scale. The kinematic measurements were performed by the so called grid method. In order to produce the gratings, direct interferential photolithography was used. The gratings were digitized through the use of a white-light interferometric microscope. An adapted image stitching algorithm, applied to the phase maps, has been developed and implemented in order to extend the size of the region of interest. With this method, and by paying a particular attention to the conduct of the mechanical tests, the strain resolution obtained ranges from 1 to $2 \times 10^{-3}$ for a spatial resolution of about $20 \mu \mathrm{m}$. In this paper, the method was applied to the study of the onset of local elasto-plastic strains in a ferritic steel coupon. The results show that the method is well suited to study small localized strains, for which few alternatives exist. To the best knowledge of the authors, it is the first time that white light interferometric microscopy is used to measure full-field strains. The technique is reasonably easy to set up although a number of limitations exist. The paper is concluded by some considerations about further work required to extend the range of applicability of the method.
\end{abstract}

Keywords: Full-field measurements, strain measurements, micrometric scale, white-light interferometric microscopy, microplasticity

\section{Introduction}

For a better understanding of the mechanical behaviour of materials, it is necessary to study the physical phenomena taking place at the scale of its heterogeneities. Indeed, the global behaviour of a bulk material can be predicted from relevant microscopic data using homogenization schemes. A number of powerful techniques are nowadays available but, in this context, the major difficulty remains the experimental determination of the local properties. Obviously, the characterization of the individual constituents of a material is not enough to predict the global mechanical properties since the interactions that are often at the origin of the macroscopic behaviour are not taken into account. Consequently, the development of quantitative displacement and strain field measurement techniques at this scale is an important field that very much remains an open problem. This work is a contribution to this problem with the specific view to detect the onset of microplasticity. This topic has seldom been addressed until now. In the literature, only a few papers can be found. Guo et al. [2006] studied the plastic behaviour of a coarse-grained polycristalline aluminium alloy (grain dimension in the millimeter range) under tensile test over a region of a few square centimeters. To achieve this purpose, they used moiré interferometry. By plotting the stress/strain curves for each grain of the region of interest, they eventually managed to show the heteregoneity on the longitudinal strain directly dependent from the microstructure (relative values of strain varying from 1 to 3 or 4). Nicoletto [2002] also studied strain fields of an aluminium alloy thanks to moiré interferometry. He used a notched coupon under tensile load and followed the strain maps over a small region of interest (about a few square millimeters) at the vicinity of the notch. The author managed to put in evidence the heterogeneous nature of the plastic strains due to both the microstructure and the geometry of the

\footnotetext{
${ }^{*}$ Corresponding author

Email addresses: raphael.moulart@chalons.ensam.fr (Raphaël Moulart), rene.rotinat@chalons.ensam.fr (René Rotinat), fabrice.pierron@chalons.ensam.fr (Fabrice Pierron)
} 
sample. Eventually, he concluded: "Moiré interferometry with microscopic inspection appears to be a valuable technique to visualize heterogeneous deformation in coarse-grained polycrystalline metals in the elastic and plastic range". Lagattu et al. [2006] studied the strain fields in a two-phased titanium alloy commonly used for aerospace applications under tensile load. They applied digital image correlation (DIC) with SEM images leading to a spatial resolution of $1 \mu \mathrm{m}$ for an observed field of $70 \times 50 \mu \mathrm{m}^{2}$. The authors noted that the largest strains were obtained for the primary nodules of the $\alpha$ phase which is in accordance with the theory. Kang et al. [2007] also measured the microscopic strain distribution of a biphasic steel alloy at the grain scale, using DIC and scanning electron microscopy topography images. Their results showed the heterogeneity of the strain maps especially between the ferritic and martensitic phases. They also showed that heat treatment redistributes strains between martensite and ferrite. Unfortunately, the proposed approach is only applied to large strains. Héripré et al. [2007] performed a micromechanical study coupling experimental data and FE simulation. The main originality of this work is to couple full-field strain measurements (using DIC on microgrids with a scanning electronic microscope) with an in-depth microstructural study involving grain orientations through EBSD. The strain fields obtained through in-situ mechanical test were compared to the numerical strains obtained with FE analysis. The microstructural laws used to perform the FE calculation have been updated so as to be in accordance with experimental results. Another interesting study released very recently concerns the use of digital image correlation to investigate the fatigue damage in duplex steels El Bartali et al. [2008]. Optical microscopy was used and specific damage mechanisms observed on SEM pictures were backed up by local strain measurements. Several other papers can be found in the literature that address the heterogeneous deformation of metals at the microstructural level but they are mainly targeted at large deformations, for instance Allais et al. [1994]. Finally, an interesting paper is Bonavolontà et al. [2007]. The authors used the magneto-mechanical coupling effect through the use of a SQUID (superconducting quantum interference device) microscope to localize the plastic strains of in structural steel specimens under tensile load. The field of view is about a few tens of square millimeters. With this method, magnetic dislocation motion arising from tensile stress can be detected and thus plastic deformation can be localized (without quantifying it). The authors conclude about the relevance of the proposed method to investigate failure mechanisms in structures as a non-destructive tool.

The present paper uses an original alternative to the above technique, with the hope to reach the right compromise between resolution and spatial resolution to study the transition between elastic and local micro-plastic behaviour. The longer term target is to provide quantitative strain measurements to couple with heat dissipation measurements Maquin and Pierron [2009] in order to establish an energy balance to study high cycle fatigue. The novelty of the measurement technique lies in the fact that a white light interferometer is used to digitize the surface profile of the tested specimen, which, to the best knowledge of the present authors, has never been reported before in the literature. The main advantages of this technique are the insensitivity of the in-plane measurements to out-of-plane movements (very low depth of field in optical microscopy) and the fact that it is easier to bring a test machine to this microscope than to perform tests in an SEM. The drawback compared to SEM or AFM based measurements is that the spatial resolution will be limited to the micrometer range because of the use of white light. The pattern to be digitized can be either a random pattern (natural or enhanced surface roughness of the specimen) or a periodic pattern (grid). The latter is selected here in order to obtain the best possible performances at the cost of having to print a grid at the specimen surface. The technique is reported in details in Moulart et al. [2007] where a thorough literature review on micro and nanoscale full-field measurements can also be found. The present paper is an application of this technique to the study of the onset of plastic strain localization at the scale of the grains in a ferritic steel.

\section{Full-field measurement}

In this first section, the principle of the full-field measurement method is briefly recalled.

\subsection{The micro grid method [Moulart et al. [2007]]}

In order to measure the displacement field at the surface of a specimen at the micrometric scale, the grid method was adapted. It consists in analyzing the deformation of a periodic pattern deposited onto the surface to study by a spatial phase stepping algorithm [Surrel, 1994].

For this purpose, a first stage of grid marking has to be implemented. Several lithographic processes exist and allow to obtain micrometric gratings [Dally and Read, 1993, Xie et al., 2003, Allais et al., 1994, Schroeter and McDowell, 
2003]. Direct interferometric photolithography was selected here. This technique consists in recording the parallel interference fringes of two collimated laser beams on a photoresist layer spread onto the surface to study. Thus, the pitch can easily be adjusted depending only on the wavelength of the light and the angle between the two incident beams interfering on the sample. In order to obtain cross gratings (so as to have access to both components of the in-plane displacement), the process is simply repeated after rotating the sample by $90^{\circ}$.

Then, these gratings must be digitized at every step of the loading. To do that, and considering the typical size of the pitches (i.e. a few micrometers), optical techniques can be used for their simplicity and their high speed of recording (to be compared with the ones of electronic and probe microscopy). In this study, a white-light interferometric microscope has been chosen. Based on short length coherence interferences concepts, it allows to digitize the 3D profile of a sample with a subnanometric resolution in the vertical direction and with a spatial resolution limited by the diffraction limit (typically defined by the Sparrow criterion) [Wyant, 2002]. In practice, pitches down to $2 \mu \mathrm{m}$ can be used. It is important to note that the surface must also be reasonably reflective to use such a microscope. Another important feature is the fact that the measured profile depends solely on the internal distance in the lens between a semi transparent lens and the imaging plane. Therefore, not only will the out-of-plane displacements be recorded at the same time as the in-plane ones, but the latter will be independent from the former. This is one of the main advantages of this procedure compared to optical microscopy where the very low depth of field is clearly a problem (as mentioned in El Bartali et al. [2008], for instance).

These profile images can then be processed by the specific spatial phase-shifting algorithm of the grid method [Surrel, 1996]. Indeed, considering the sample grating as a periodic signal, it is possible to compute the phase value of this signal for each period [Surrel, 2000]. It can be demonstrated that, between two stages of loading, the displacement of a point is directly proportional to the differences of phases of the grating between these two stages:

$$
\left\{\begin{array}{l}
u_{x}(x, y)=-\frac{p}{2 \pi} \Delta \phi_{x}(x, y) \\
u_{y}(x, y)=-\frac{p}{2 \pi} \Delta \phi_{y}(x, y)
\end{array},\right.
$$

where $u_{x}(x, y)$ and $u_{y}(x, y)$ are respectively the displacement values in the $x$ and $y$ directions of a point of coordinates $(x, y), p$ is the pitch of grating and $\Delta \phi_{x}(x, y)$ and $\Delta \phi_{y}(x, y)$ are the differences of phases of point $(x, y)$ respectively in the $x$ and $y$ directions.

In this way, it is possible to obtain for a complete mechanical test the maps of the displacement with a spatial resolution equal to the pitch of the grating.

The complete details of this technique can be found in a recent paper by the present authors [Moulart et al., 2007].

\subsection{Strain calculation}

In the previous section, the method used to obtain displacement fields has been described. From these fields and to get access to mechanical parameters, strain fields have to be calculated. For that, and considering that experimental data are noisy, it is necessary to use an appropriate smoothing procedure. Several approaches exist.

- First, the global least square method can be used [Bulhak and Surrel, 2001]. With this method, the strain at a given pixel is considered to be the slope of the best fitting plane over a square of $\mathrm{P} \times \mathrm{P}$ pixels. Its main advantage is to be rather simple but the performances are limited. Higher order functions could be used to improve it.

- The displacement fields can also be smoothed using a global function such as a polynomial that can then be analytically differentiated [Moulart et al., 2006]. This is well-suited for low spatial frequency displacement maps but one can note propagation of errors and reconstruction problems at the edges of the maps.

- Strain maps can be obtained from displacement maps by using boundary integrals [Allais et al., 1994].

- A finite element smoothing and differentiation approach can also be used [Avril and Pierron, 2007]. It is very efficient when combined to inverse identification procedures but unfortunately, the reconstruction is mesh dependent. 
Here, it has been chosen to use a diffuse approximation method [Nayroles et al., 1992, Avril et al., 2008].

In this method, the displacement at the point of coordinates $(x, y)$ is considered as a Taylor expansion at the second order of the reconstructed displacements $\widetilde{U}\left(x_{i}, y_{i}\right)$ and $\widetilde{V}\left(x_{i}, y_{i}\right)$ at the closely positioned point of coordinates $\left(x_{i}, y_{i}\right)$, called a reconstruction point:

$$
\left\{\begin{aligned}
U(x, y) & =\widetilde{U}\left(x_{i}, y_{i}\right)+\xi \frac{\partial \widetilde{U}}{\partial x}\left(x_{i}, y_{i}\right)+\eta \frac{\partial \widetilde{U}}{\partial y}\left(x_{i}, y_{i}\right)+\frac{1}{2} \xi^{2} \frac{\partial^{2} \widetilde{U}}{\partial x^{2}}\left(x_{i}, y_{i}\right) \\
& +\frac{1}{2} \eta^{2} \frac{\partial^{2} \widetilde{U}}{\partial y^{2}}\left(x_{i}, y_{i}\right)+\xi \eta \frac{\partial^{2} \widetilde{U}}{\partial x \partial y}\left(x_{i}, y_{i}\right)+o\left(\xi^{2}, \eta^{2}\right) \\
V(x, y) & =\widetilde{V}\left(x_{i}, y_{i}\right)+\xi \frac{\partial \widetilde{V}}{\partial x}\left(x_{i}, y_{i}\right)+\eta \frac{\partial \widetilde{V}}{\partial y}\left(x_{i}, y_{i}\right)+\frac{1}{2} \xi^{2} \frac{\partial^{2} \widetilde{V}}{\partial x^{2}}\left(x_{i}, y_{i}\right) \\
& +\frac{1}{2} \eta^{2} \frac{\partial^{2} \widetilde{V}}{\partial y^{2}}\left(x_{i}, y_{i}\right)+\xi \eta \frac{\partial^{2} \widetilde{V}}{\partial x \partial y}\left(x_{i}, y_{i}\right)+o\left(\xi^{2}, \eta^{2}\right)
\end{aligned}\right.
$$

where $\xi=x-x_{i}$ and $\eta=y-y_{i}$.

This corresponds to a local fitting by a second order polynomial, with twelve unknowns at each reconstruction point (six for each component of displacement). In the previous equation, the unknowns are the variables appearing at the right side (i.e. the terms of the Taylor expansion) whereas $U(x, y)$ and $V(x, y)$ are the measured values of the displacement respectively in the $x$ and $y$ directions at the point $(x, y)$. The unknown values of displacements and gradients can be computed on any reconstruction grid. Here, for the sake of convenience, they will be reconstructed at every measurement point (using the natural grid of the periods of the grating). For this, a local weighted least square regression is used [Cleveland and Loader, 1996]. The Taylor expansion of equation 2 is considered to be valid only in a rectangular window centered on the considered point $\left(x_{i}, y_{i}\right)$ and whose dimensions are $R_{x}$ and $R_{y}$ respectively in the $x$ and $y$ direction (Fig. 1(a)). Here, $R_{x}$ will be set equal to $R_{y}$ and this parameter will be called the critical radius. In this square window of influence, the weighting function is defined as a bicubic function called $w(x, y)$ (Fig. 1(b)):

$$
\begin{aligned}
w(x, y) & =\left[2\left(\frac{\left|x-x_{i}\right|}{R_{x}}\right)^{3}-3\left(\frac{\left|x-x_{i}\right|}{R_{x}}\right)^{2}+1\right] \\
& \times\left[2\left(\frac{\left|y-y_{i}\right|}{R_{y}}\right)^{3}-3\left(\frac{\left|y-y_{i}\right|}{R_{y}}\right)^{2}+1\right] .
\end{aligned}
$$

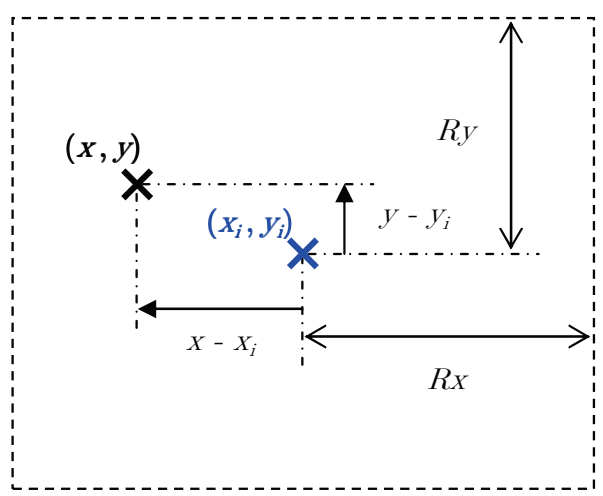

(a) Influence windows

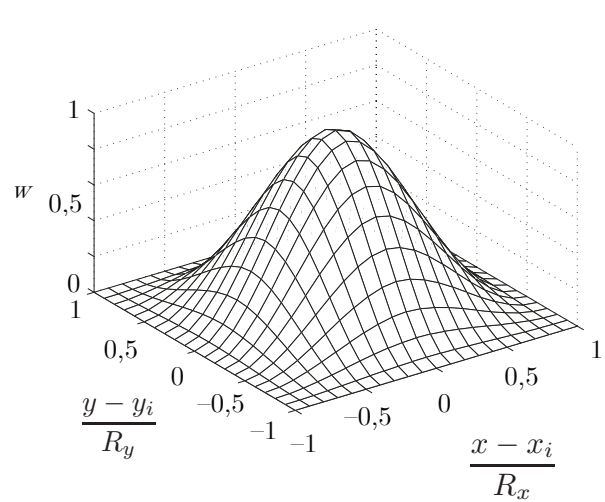

(b) Weight function

Figure 1: Principle of the diffuse approximation

The objective of this weighting function is to add some regularization by ensuring continuity of the reconstructed field up to the first derivatives [Nayroles et al., 1992, Avril et al., 2008]. By minimizing the weighted square deviation 
between the measured displacement at every influence point and their displacement value generated from the Taylor expansion, the twelve unknowns of equation 2 are identified. The strain values at each reconstructed point are directly obtained by:

$$
\left\{\begin{array}{rl}
\varepsilon_{x x}\left(x_{i}, y_{i}\right) & =\frac{\partial \widetilde{U}}{\partial x}\left(x_{i}, y_{i}\right) \\
\varepsilon_{y y}\left(x_{i}, y_{i}\right) & =\frac{\partial \widetilde{V}}{\partial y}\left(x_{i}, y_{i}\right) \\
\varepsilon_{x y}\left(x_{i}, y_{i}\right) & =\frac{1}{2} \times\left(\frac{\partial \widetilde{U}}{\partial y}\left(x_{i}, y_{i}\right)+\frac{\partial \widetilde{V}}{\partial x}\left(x_{i}, y_{i}\right)\right)
\end{array} .\right.
$$

In the previous equation, the small strain assumption is used. It was checked that no large rotations occurred experimentally.

\subsection{Strain resolution}

The strain resolution is deduced from the displacement resolution. For a full-field measurement method, the latter is often considered to be the standard deviation of the noise. By applying a smoothing/differentiation algorithm to the noise maps, it is possible to determine the strain resolution as the standard deviation of the generated "noisy-strain" maps [Pierron et al., 2007a].

The previous study has shown that for a pitch of $5.6 \mu \mathrm{m}$ observed with a $25 \times$ magnification (leading to a sampling period of 14 pixels per period), the displacement resolution is about $0.3 \%$ of the grid pitch (ie $15 \mathrm{~nm}$ ). It has also been shown that a rigid body displacement increases the level of noise that exhibits a spatial correlation [Moulart et al., 2007]. Consequently, this considerably degrades the displacement resolution. Therefore, one can expect that the strain resolution will also be affected by the rigid body motion. In order to check this, the following procedure was applied:

- recording two images of the same grating without applying any load;

- performing a numerical rigid body displacement by taking a sub-region of the first image and another (corresponding to a shift of a whole number of pixels) of the second one;

- computing the phases of these two images by the spatial phase shifting algorithm and subtracting them;

- applying the diffuse approximation algorithm on the noise map thus obtained;

- evaluating the standard deviation of the "noisy-strain" maps which is directly equal to the value of the strain resolution corresponding to the considered rigid body displacement.

By applying this procedure for an imposed numerical displacement varying between 0 and 4 periods and for different sizes of critical radii (pitch: $5.6 \mu \mathrm{m}$, magnification: $25 \times$ ), the graphs in figure 2 are obtained. It can be seen that the strain resolution increases with the rigid body displacement. It can also be seen that the larger the critical radius, the lower the strain resolution, which was as expected. Nevertheless, it should be kept in mind that the critical radius cannot be increased too much as it conditions directly the spatial resolution. Consequently, it will be necessary to find a compromise between the desired strain and spatial resolutions (depending on the size of the heterogeneities of the tested material). It can also be concluded that the rigid body motion will have to be contained in strict limits to be able to study the physical phenomena with an appropriate resolution. This last remark is all the more important that the "noisy-strain" maps show a spatial correlation that could be easily confused with a physical localization phenomenon (Fig. 3).

By using a critical radius of 4 and by keeping the rigid body motion within half of the pitch, a strain resolution of about $2 \times 10^{-3}$ can be expected. This value will be used to process the test results presented in the following.

\section{Testing configuration}

In this section, all the conditions that have been used to perform the mechanical tests are reviewed. 


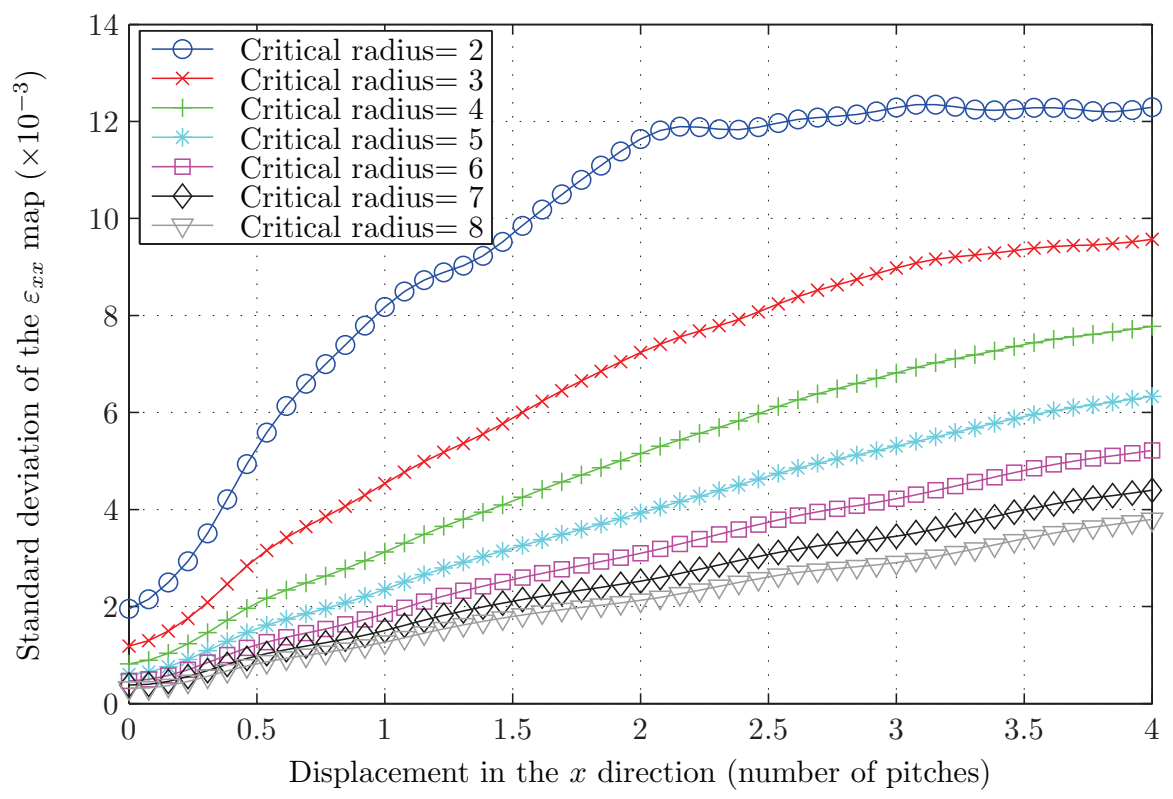

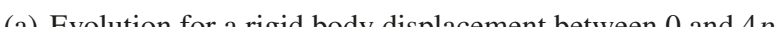

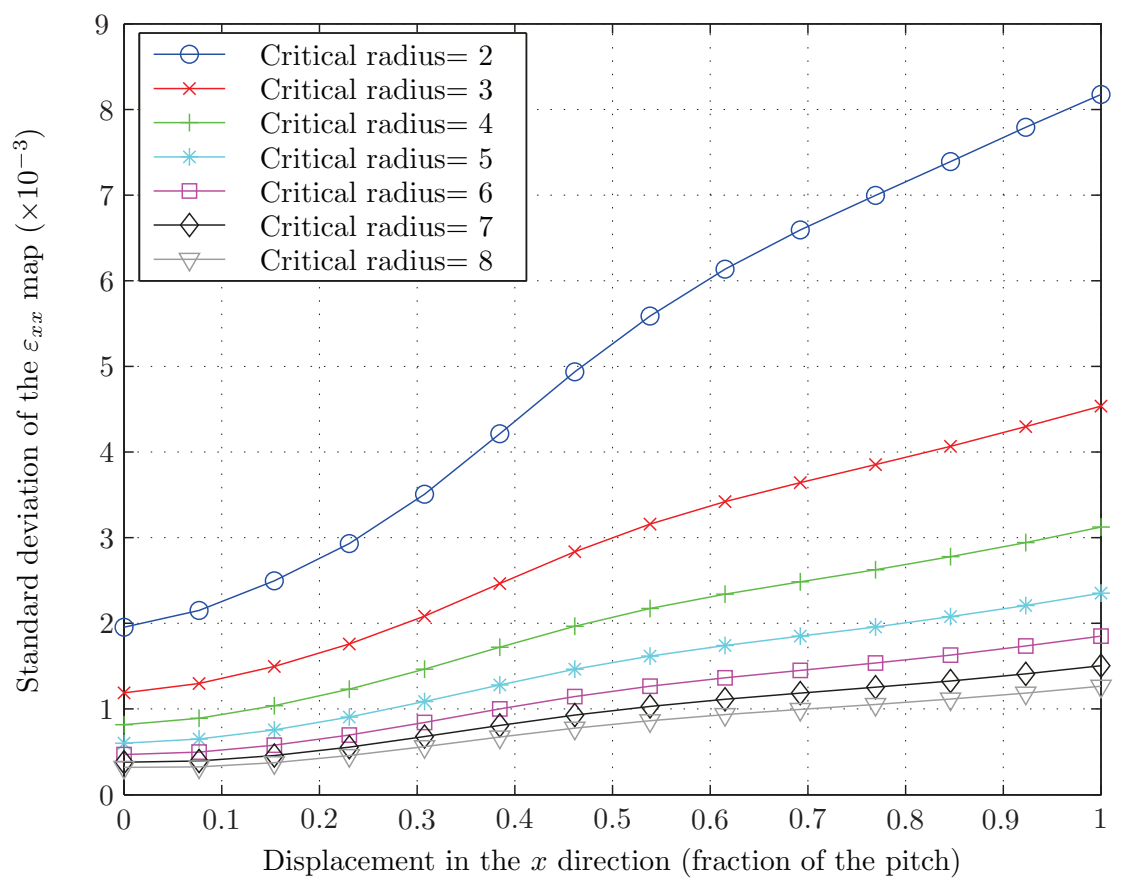

(b) Evolution for a rigid body displacement between 0 and $p$

Figure 2: Evolution of the strain resolution against the rigid body motion and the critical radius for the diffuse approximation (using the $50 \times$ lens coupled with the $0.5 \times$ zoom). 




(a) $\varepsilon_{x x} \operatorname{map}\left(\times 10^{-3}\right)$

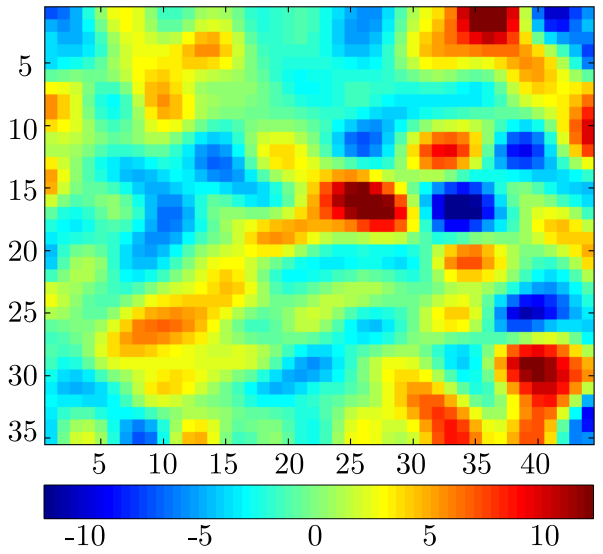

(b) $\varepsilon_{y y} \operatorname{map}\left(\times 10^{-3}\right)$



(c) $\varepsilon_{x y} \operatorname{map}\left(\times 10^{-3}\right)$

Figure 3: Strain maps obtained for a numerical rigid body displacement in the $x$ direction of $4 p$ for a critical radius of 4 periods (using the $50 \times$ lens coupled with the $0.5 \times$ zoom). 


\subsection{Tested sample}

The tested material is a ferritic steel. Its exact composition is given in table 1.

Obviously, this kind of material is not a structural one (because of its low mechanical properties). Nevertheless, it has been chosen for two main reasons:

- it is marketed as laminated sheets, obtained by cold-rolling, which is very convenient for the manufacturing of the samples;

- its grains have a relatively large size (a few tens of micrometers, Fig. 4(a)) which allows with the proposed method to study the micromechanical behaviour with more than ten measurement points per grain.

Table 1: Exact composition of the studied ferritic steel

\begin{tabular}{lccccccccccc}
\hline Element & $\mathrm{Mn}$ & $\mathrm{Cr}$ & $\mathrm{Al}$ & $\mathrm{Ni}$ & $\mathrm{Si}$ & $\mathrm{S}$ & $\mathrm{P}$ & $\mathrm{C}$ & $\mathrm{Cu}$ & $\mathrm{Mo}$ & $\mathrm{Ti}$ \\
\hline \% in mass & .234 & .045 & .042 & .031 & .027 & .02 & .019 & .017 & .012 & .01 & .004 \\
\hline
\end{tabular}

Its macroscopic yield point is about $150 \mathrm{MPa}$ (Fig. 4(b)).

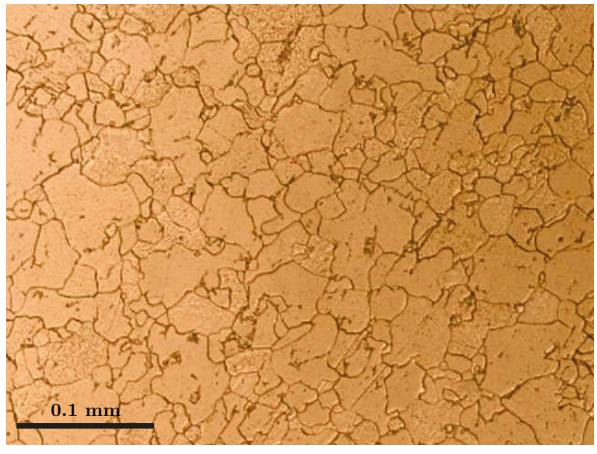

(a) Microstructure

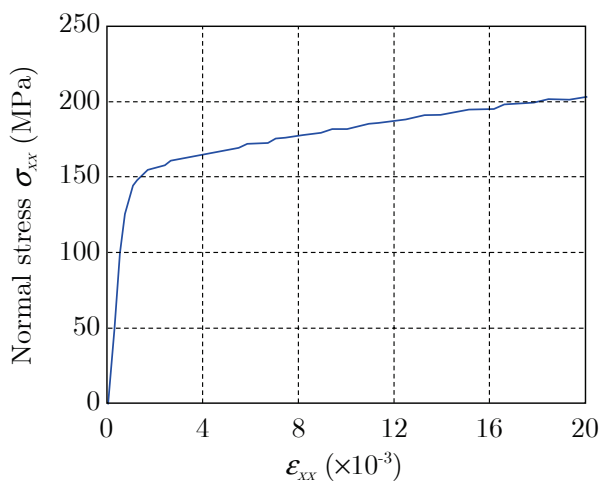

(b) Tensile curve (obtained with strain gauges)

Figure 4: Characterization of the tested material.

Considering the geometry, the sample is dogbone-shaped with a slightly variable section so as to concentrate the strains in the middle part (Fig. 5). It will be submitted to a tensile loading (with the tensile direction in the rolling direction of the material) while images of the gratings will be recorded. To perform this, a specific miniature loading machine has had to be designed and manufactured: this is the object of the next subsection.

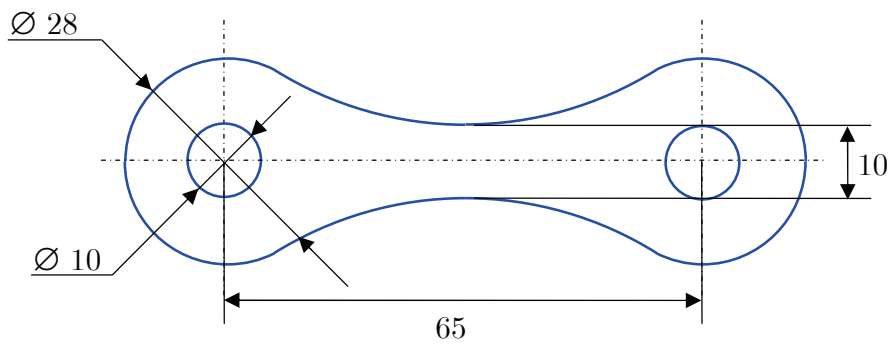

Figure 5: Geometry of the sample (dimensions in millimeters). 


\subsection{Micro testing machine}

The tensile machine has been designed so as to fit in the available space under the white-light interferometric microscope. In practice, its dimensions have been limited to $200 \times 200 \times 100 \mathrm{~mm}^{3}$. Moreover, its kinematic chain has been designed to be symmetrical with two mobile cross-heads in order to avoid as much as possible the rigid body motion in the middle part of the sample. The translation movement is ensured by two screws with a pitch of $1 \mathrm{~mm}$ which enables to obtain a pure tensile load as the axis of the sample is situated in the same plane of the axes of the screws. Moreover, the machine is driven by a step-by-step motor; the transmission of the movement is performed through a system of pulleys and a belt. The machine is shown on figure 6 . The load is precisely controlled through to a small $5 \mathrm{kN}$ load sensor with an uncertainty of $\pm 25 \mathrm{~N}$ (XFTC302, FGP sensor).

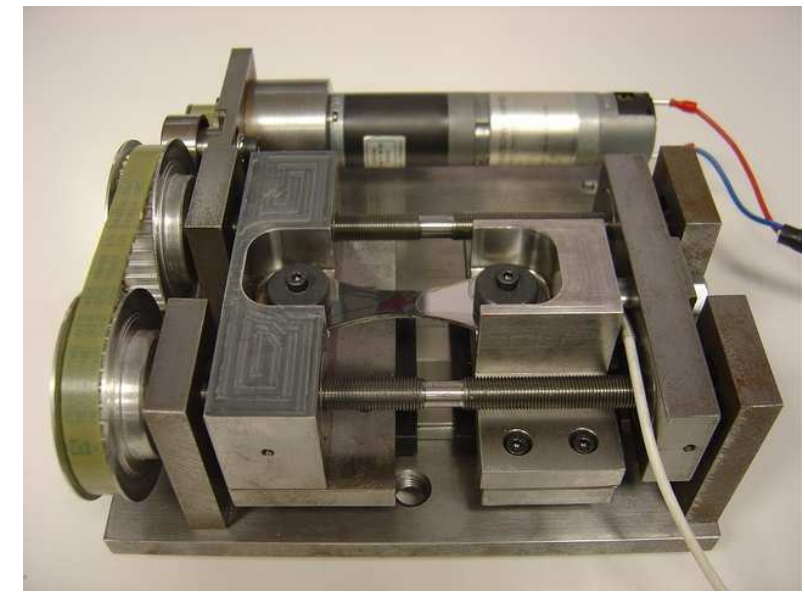

Figure 6: In-house developed miniature tensile machine.

\subsection{Correction of the rigid body motion}

In spite of the symmetrical loading system of the machine introduced in the previous subsection, the very small observed area is bound to undergo some rigid body displacements during a mechanical test. Indeed, the deformation of the specimen will induce such displacements if the observed area is not strictly in the centre. Moreover, the load cell also deforms and there might be some initial clearance adjustments. This will induce a significant increase in measurement errors, as demonstrated in subsection 2.3. It is therefore necessary to account for it, notwithstanding the fact that if the rigid body motion is too large, the initial specimen field of view will completely move away from the observed area. It has been chosen to correct these rigid body displacements during the mechanical test (that will be performed incrementally). To do so, the region of interest will be selected so that a small visual defect can be identified at a corner of the image. Between each increment of load, this visual mark will be placed back to its original location by a global displacement of the machine through the translation stage of the microscope. Then only will the deformed image be recorded by the microscope. Thus, one can expect that the global rigid body motion will not exceed half a period of the grating which leads to the best strain resolution that can be obtained $\left(2 \times 10^{-} 3\right.$ for $\left.\mathrm{R}=4\right)$. It must be emphasized that with this procedure, the actual deformation field are recorded with a superimposed rigid body displacement that disappears after differentiation.

\subsection{Observation of the microstructure}

In order to correlate the computed strain maps with the microstructure of the material in the region of interest, it is necessary to spatially locate it. Indeed, it is not possible to observe the microstructure while the mechanical test is underway because of the grating. The solution is therefore to observe it after the test. This is possible since the strains remain low and, consequently, the microstructure can be considered to be the same before and after the test.

In order to locate the region of interest, a small punch mark is performed close to the edge of the sample (so as not to disturb the region of interest) and the coordinates of the region of interest relative to this mark are recorded thanks 
to the indexation of the stage of the microscope, with a resolution of $1 \mu \mathrm{m}$ (Fig. 7). Thus, after performing the tensile test, the grating is dissolved with acetone and a chemical attack is performed. The microstructure of the considered region is then observed by repositioning it under the microscope using the punch mark. Finally, the grain boundaries can be drawn on the strain maps.

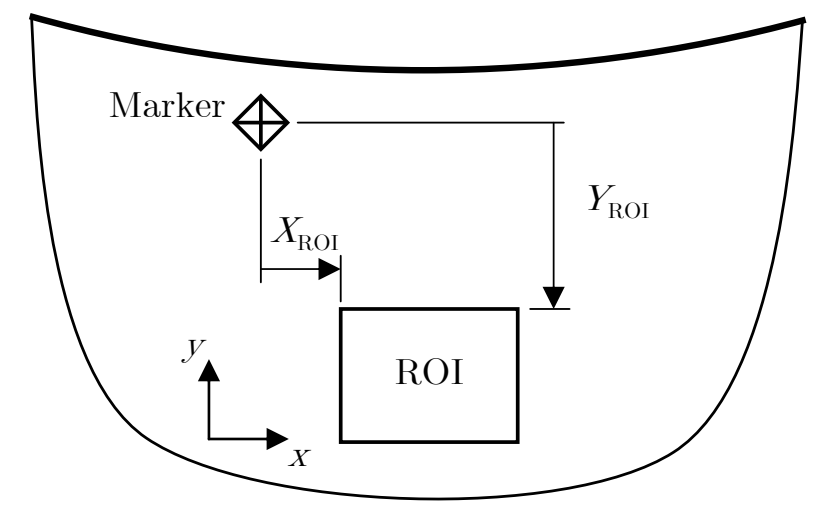

Figure 7: Indexing the position of the region of interest (ROI).

\subsection{Stitching}

One major limitation of the proposed method is the fact that for the high magnifications generally used to make measurements at the grain size (x25, typically), the field of view is rather small (about 300 by 200 micrometer square). A possible way to overcome this limitation is to use a stitching algorithm that allows to stitch several images of different adjacent regions together. This is obviously only possible for static behaviour since in this case, the image recording can be rather long (but still much less than for SEM measurements). The softwares driving white-light interferometric microscopes usually propose a stitching function (using an image correlation algorithm). With these functions, the principle is to put together two or more images from the interferometric microscope that are partially overlapping; nevertheless, there are some reconstruction errors that are not necessarily very disturbing when using directly the images for surface roughness information but with the present method, the phase calculation will be strongly affected by reconstruction errors in the overlapping regions.

Fortunately, in the present situation, one can take advantage of the a priori information provided by the periodical signal. This is why a specific stitching algorithm was developed, based on the stitching of the phase maps instead of the raw profile images. The principle is the following (Fig. 8).

- First of all, images of the different regions are recorded in such a way that they are partially overlapping (typically 10 to $20 \%$ ).

- The phases of the different individual images are computed thanks to the spatial phase shifting algorithm (Fig. 8(a)).

- These phases are then unwrapped using the default unwrapping function of Matlab — which is possible as the phase maps are not too noisy; if it was not the case, a more powerful unwrapping algorithm should be used (Fig. 8(b)).

- The average difference of the phases in the overlapping region of two images is calculated (Fig. 8(c)).

- This difference is then subtracted to each of the two considered phase maps (Fig. 8(d)).

- The stitched phase is finally obtained by putting together the two corrected phase maps (Fig. 8(e)). 


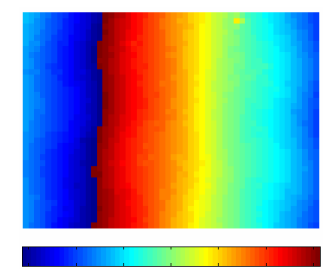

0

(a) Individual wrapped phases

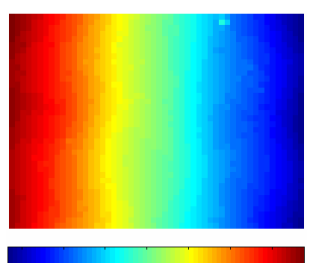

$-8$

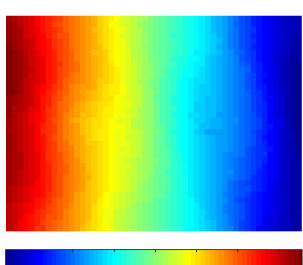

$-8$

(b) Individual unwrapped phases
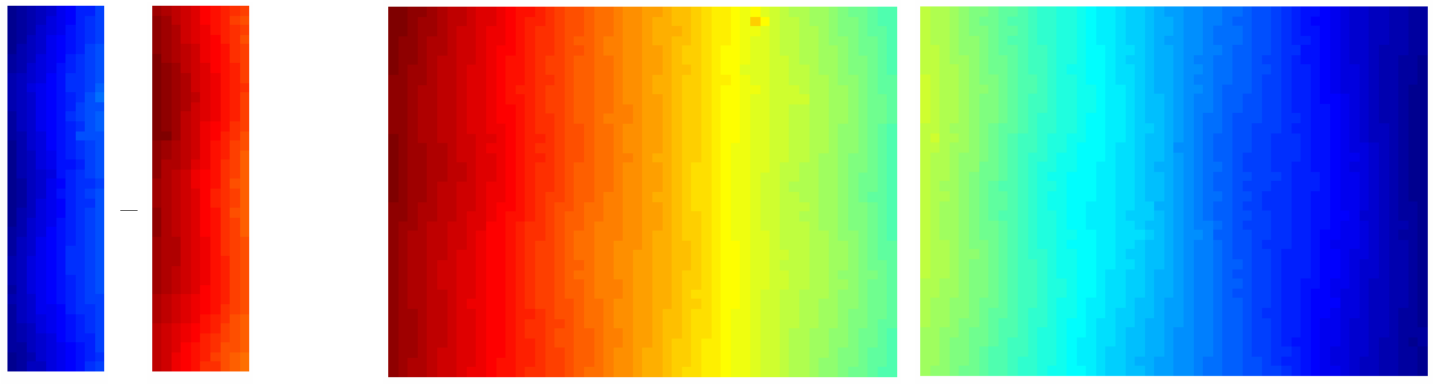

$\begin{array}{llll}-8 & -2 & -8 & -2\end{array}$

(c) Overlapping regions substraction

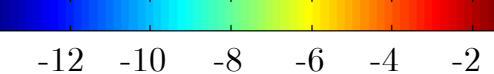

$\begin{array}{llllll}-12 & -10 & -8 & -6 & -4 & -2\end{array}$

(d) Individual unwrapped phases with $\phi_{2}$ redimensioned
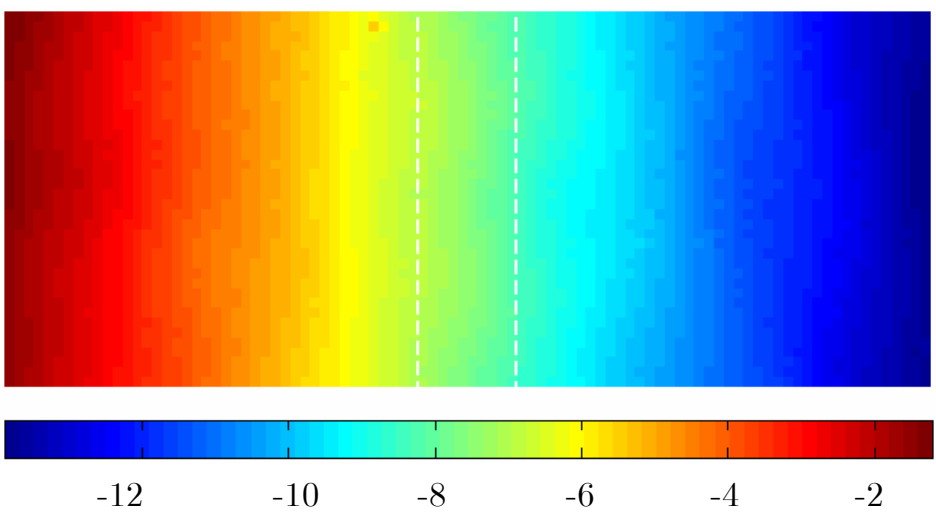

(e) Stitched phase obtained

Figure 8: Principle of the phase stitching. 
The same procedure is repeated as many times as necessary to reconstruct the complete stitched phase maps.

It should be noted that the subtraction operation does not affect the results as the phases are then subtracted to obtain displacement maps and differentiated to get the strain maps. It has been verified that there was no strain reconstruction error in the overlapping region: Fig. 9 shows a $\varepsilon_{x x}$ noise map (i.e. a strain map obtained from a noise map). The dashed lines are materializing the overlapping region. It can be seen on this map that there is no noticeable variation of the localization of the noise between the overlapping region and the other ones. Moreover, the standard deviations of the resulting strain noise on both regions (overlapping and outside) are more or less the same $\left(5.4 \times 10^{-5}\right.$ in the overlapping region, $5.9 \times 10^{-5}$ in the other ones), which confirms that the stitching algorithm performs very well here.

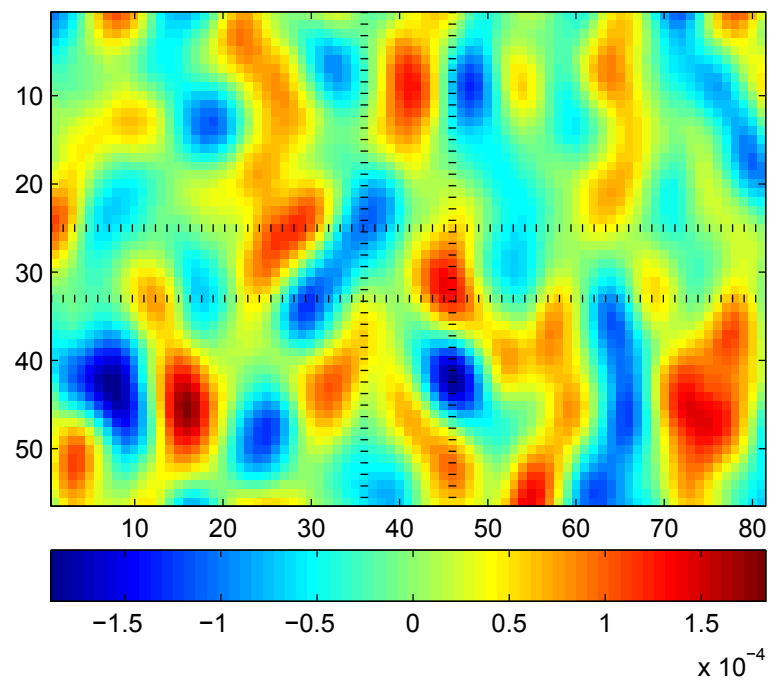

Figure 9: $\varepsilon_{x x}$ map strain map obtained from a stitched noise map (using the $50 \times$ lens coupled with the $0.5 \times$ zoom).

With this technique, images with a good spatial resolution (by using high magnification) and with a larger field of view (potentially unlimited) can be obtained.

The procedure is now complete in order to proceed to the test in the best conditions. The next section will present the first mechanical test results on the considered steel samples.

\section{Results and discussion}

The previous test procedure has been applied to the considered steel sample with the $50 \times$ lens of the white-light interferometric microscope coupled with the $0.5 \times$ zoom (thus giving a global magnification of $25 \times$ ). $2 \times 2$ stitching with an overlap of $20 \%$ was used (which leads to a field of view of $450 \times 340 \mu \mathrm{m}^{2}$ ).

The sample has been tested up to a global longitudinal strain of $5.5 \times 10^{-3}$ in 40 stages. In order to validate the strain measurements, a unidirectional strain gauge was positioned on the opposite specimen face. Figure 10 shows the global stress/strain curve and the three in-plain strain maps for three stages of the loading.

In order to compare to the strain gauge readings, the average longitudinal strain was computed from the full-field strains. The results show a good overlap of the two strain data, even for very small strains thanks to the averaging effect. This method is therefore an excellent way of producing tiny "strain gauges". However, the interesting information is the spatial distribution of the strains over the field of view. It can be seen that up to the end of the global linear behaviour (about $100 \mathrm{MPa}$ ), the strain state is homogeneous (though a possible heterogeneity resulting in strains below the strain resolution could obviously not be detected). At about $0.2 \%$ of global strain (which is the macroscopic conventional elastic limit), some significant strain localization occurs. The locations of high and low strains are confirmed on the subsequent maps, as shown for the last measurement step. One can also notice that the zones of high longitudinal tensile strain correspond to the zones of high transverse compression strains and the other 


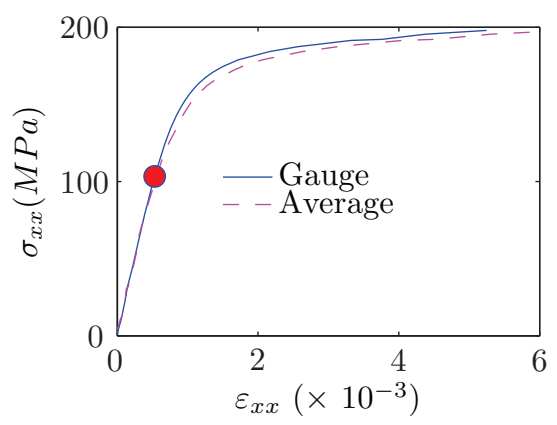

(a) Step 1: $\sigma=f(\varepsilon)$ curve



(d) Step 1: $\varepsilon_{x x}\left(\times 10^{-3}\right)$

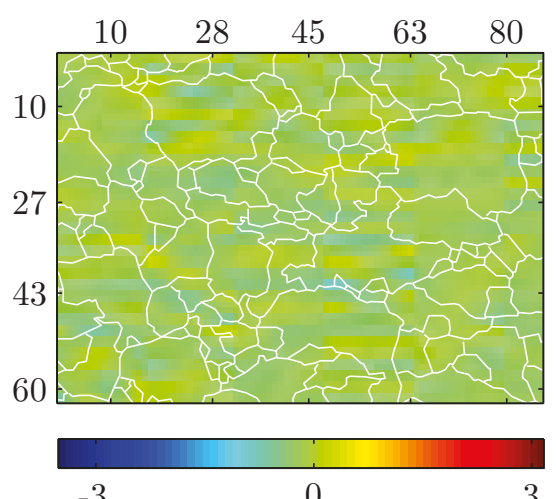

(g) Step 1: $\varepsilon_{y y}\left(\times 10^{-3}\right)$

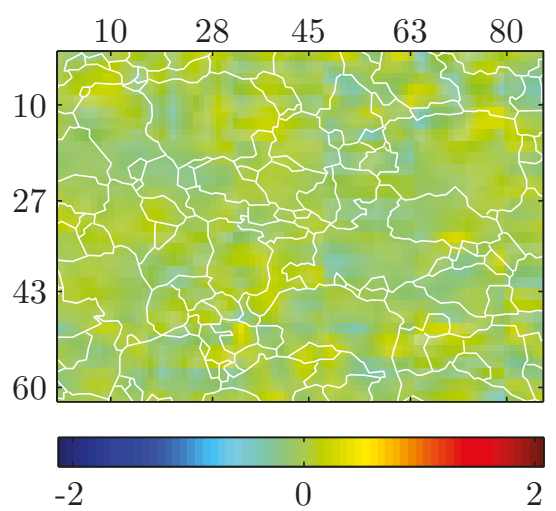

(j) Step 1: $\varepsilon_{x y}\left(\times 10^{-3}\right)$

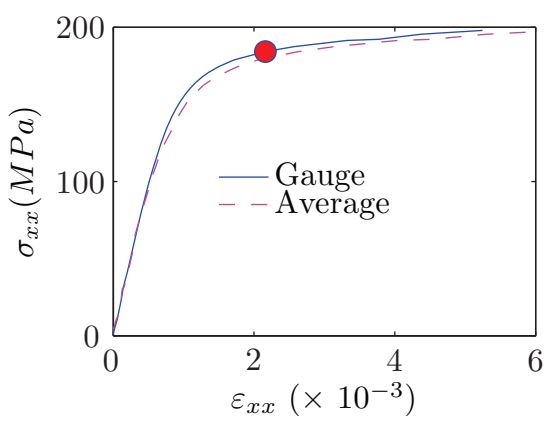

(b) Step 2: $\sigma=f(\varepsilon)$ curve

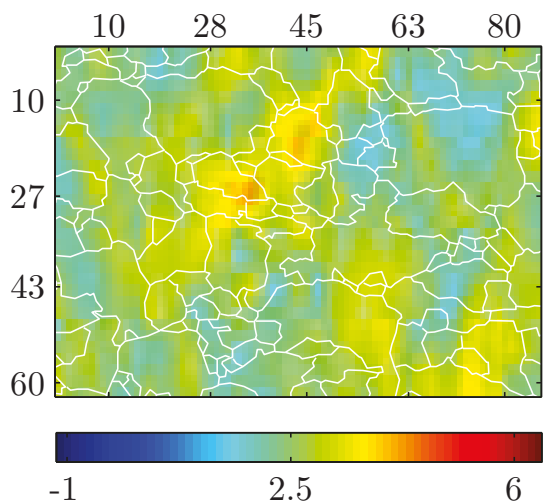

(e) Step 2: $\varepsilon_{x x}\left(\times 10^{-3}\right)$

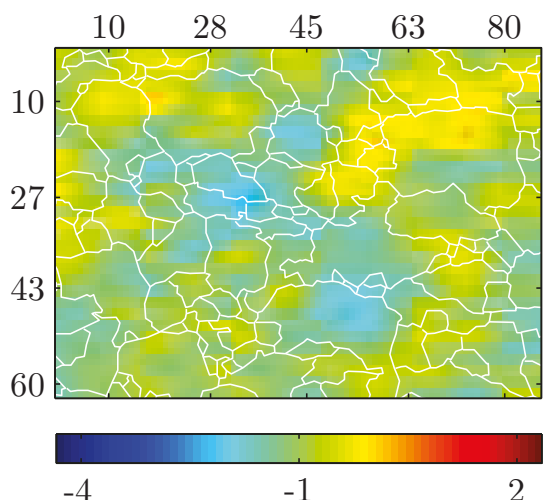

(h) Step 2: $\varepsilon_{y y}\left(\times 10^{-3}\right)$



(k) Step 2: $\varepsilon_{x y}\left(\times 10^{-3}\right)$

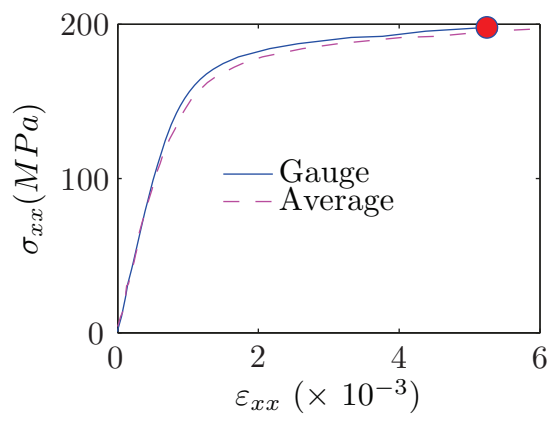

(c) Step 3: $\sigma=f(\varepsilon)$ curve

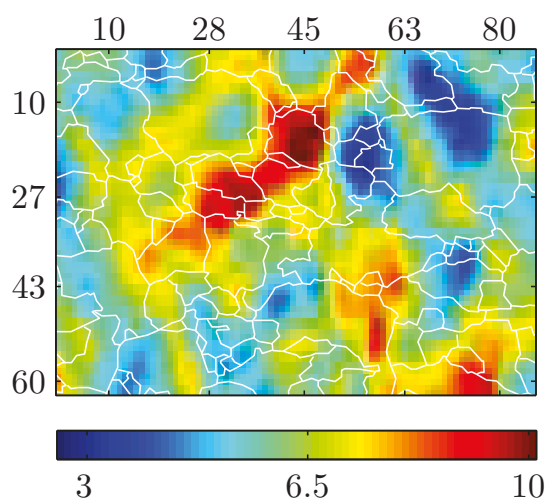

(f) Step 3: $\varepsilon_{x x}\left(\times 10^{-3}\right)$

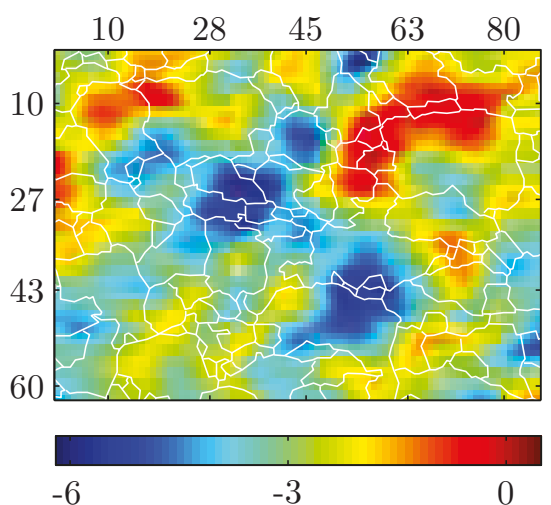

(i) Step 3: $\varepsilon_{y y}\left(\times 10^{-3}\right)$

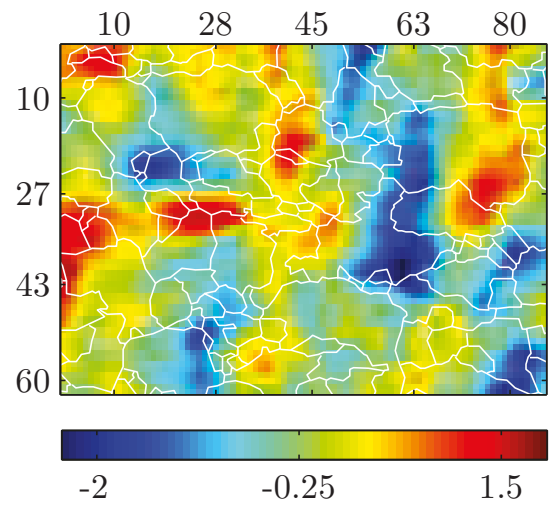

(1) Step 3: $\varepsilon_{x y}\left(\times 10^{-3}\right)$

Figure 10: Results of a mechanical test on the ferritic steel specimen with $2 \times 2$ stitching (grating pitch: $5.6 \mu$ m; magnification: $25 \times$ ). 
way round, and that the shear strain component, though significant, remains very small with respect to the normal strains. This can be investigated more precisely by computing the principal strain directions.

\subsection{Principal strains}

It would be very interesting to have access to the strain tensor expressed not in the global coordinate system $(x, y)$ but in a local coordinate system attached to the crystallographic orientation of the grains. To do that, the knowledge of this crystallographic orientation is needed (by the use of ESBD analysis for instance) which has not been performed for the moment. But, in every pixel, the principal strain components $\left(\varepsilon_{I}\right.$ and $\left.\varepsilon_{I I}\right)$ and the orientation of the principal coordinate system $(1,2)$ (angle $\varphi$ between the $(1,2)$ and $(x, y)$ systems) can be computed through the following relations (assuming that the out-of-plane axis is also a principal direction):

$$
\begin{gathered}
\varepsilon_{I}=\frac{1}{2}\left[\varepsilon_{x x}+\varepsilon_{y y}+\sqrt{\left(\varepsilon_{x x}-\varepsilon_{y y}\right)^{2}+4 \varepsilon_{x y}^{2}}\right] \\
\varepsilon_{I I}=\frac{1}{2}\left[\varepsilon_{x x}+\varepsilon_{y y}-\sqrt{\left(\varepsilon_{x x}-\varepsilon_{y y}\right)^{2}+4 \varepsilon_{x y}^{2}}\right] \\
\varphi=\arctan \left[\frac{2 \varepsilon_{x y}}{\varepsilon_{x x}-\varepsilon_{y y}+\sqrt{\left(\varepsilon_{x x}-\varepsilon_{y y}\right)^{2}+4 \varepsilon_{x y}^{2}}}\right] .
\end{gathered}
$$

Figure 11 shows the principal strains and orientation maps for the previously presented load steps. It can be seen that, except for the first step where the noise is very influent, the $\varepsilon_{I}$ and $\varepsilon_{I I}$ maps are nearly the same as respectively the $\varepsilon_{x x}$ and $\varepsilon_{y y}$ maps. Indeed, the orientation angles are very small (as shown on the orientation maps which look like the $\varepsilon_{x y}$ maps) and do not exceed $\pm 15^{\circ}$. One can deduce from these observations that the strain state of the region of interest corresponds to an almost uniaxial stress state. This is logical as the studied material comes from a laminated sheet and thus, the grains present a preferential orientation. To underline the effect of crystallographic orientation, it would interesting in the future to use a material that does not present a preferential orientation to check the ability of the proposed method to detect it.

\subsection{Study of the localization}

In order to determine the load at which the strains start to localize, it has been chosen to plot strain maps representing the local loss of linearity, in the same way as proposed in Pierron et al. [2007b].

To perform this, the classical strain decomposition is used:

$$
\varepsilon_{\text {plastic }}=\varepsilon_{\text {measured }}-\varepsilon_{\text {elastic }}
$$

The values of $\varepsilon_{\text {elastic }}$ are obtained by extrapolating the linear response from the first load stages (up to an average longitudinal stress of $70 \mathrm{MPa}$ and through a least square regression Fig. 12)). This implicitly implies that the longitudinal stress field is considered homogeneous through the test, which is obviously a rather crude assumption. Nevertheless, this does not really affect the relevancy of the results as this procedure is only aimed at visually magnifying the local non-linear effects on the strain maps and not at exactly separating plastic from elastic strains locally.

The obtained maps show a first detectable localization for a normal stress around $160 \mathrm{MPa}$ (Fig. 13, steps 3 and following). Interestingly, no significant localization is detected between 100 and $160 \mathrm{MPa}$, even though the global stress-strain response is already non-linear. This may be caused either by insufficient spatial resolution (the events taking place are at scales less than the spatial resolution) or insufficient resolution (the heterogeneous strains are too small for the present strain resolution). Nevertheless, the present results clearly demonstrate the potential of this full-field technique to measure small localized strains, for which very few alternatives exist in the literature. 


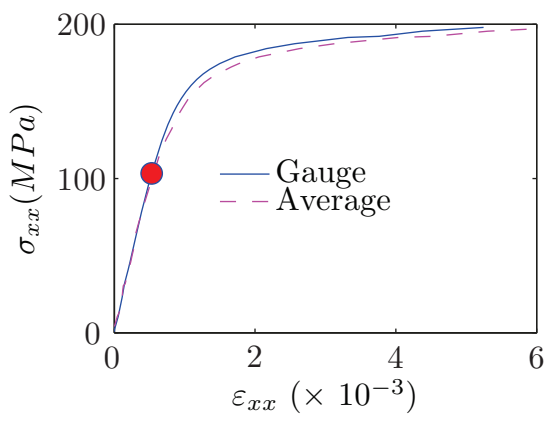

(a) Step 1: $\sigma=f(\varepsilon)$ curve



(d) Step 1: $\varepsilon_{I}\left(\times 10^{-3}\right)$

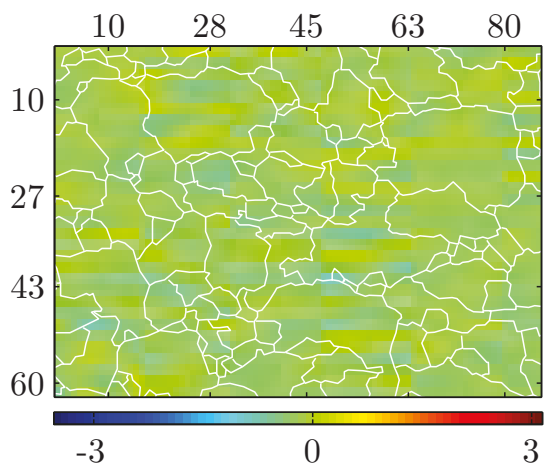

(g) Step 1: $\varepsilon_{I I}\left(\times 10^{-3}\right)$

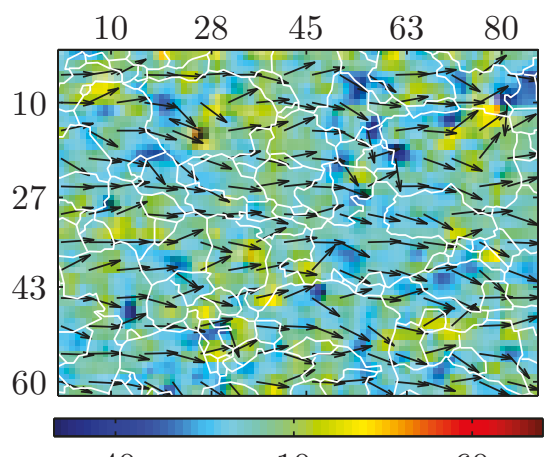

$-40$

10

60

(j) Step 1: Principal reference orientation (o)

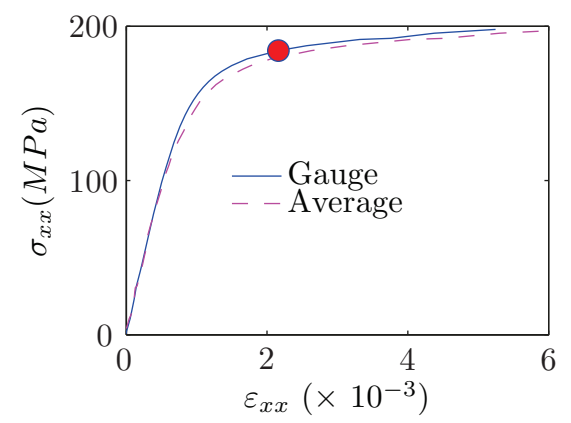

(b) Step 2: $\sigma=f(\varepsilon)$ curve



(e) Step 2: $\varepsilon_{I}\left(\times 10^{-3}\right)$

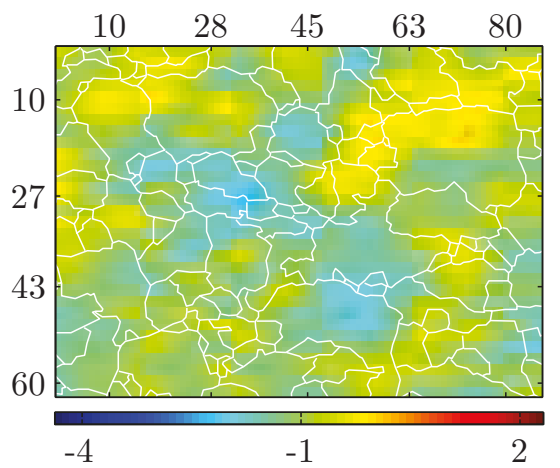

(h) Step 2: $\varepsilon_{I I}\left(\times 10^{-3}\right)$

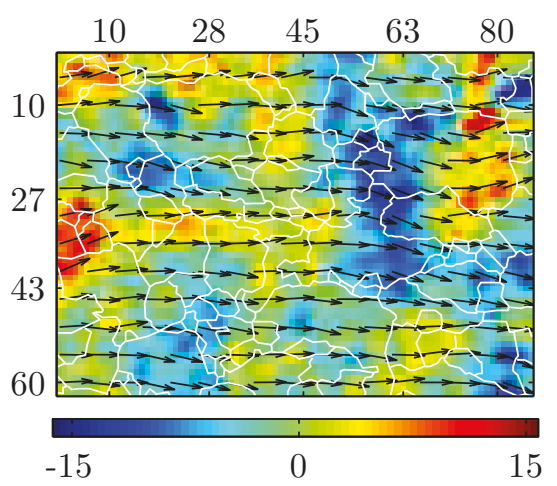

(k) Step 2: Principal reference orientation

(o)



(c) Step 3: $\sigma=f(\varepsilon)$ curve

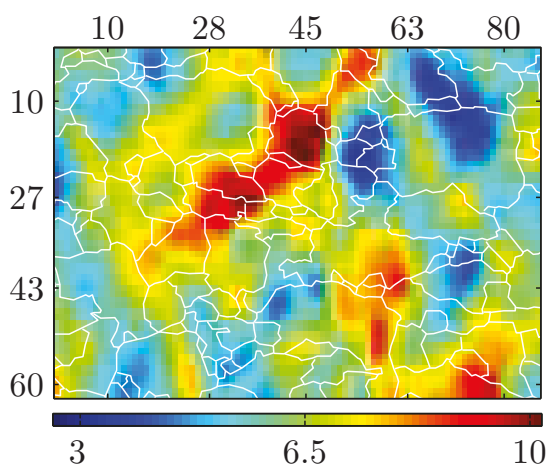

(f) Step 3: $\varepsilon_{I}\left(\times 10^{-3}\right)$

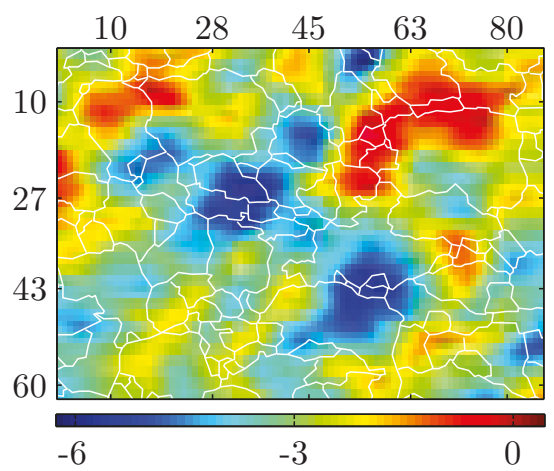

(i) Step 3: $\varepsilon_{I I}\left(\times 10^{-3}\right)$



(1) Step 3: Principal reference orientation (०)

Figure 11: Principal strain maps $\left(\varepsilon_{I}\right.$ et $\left.\varepsilon_{I I}\right)$ and principal axes orientation for a tensile test on the ferritic steel specimen with $2 \times 2$ stitching (grating pitch: $5.6 \mu \mathrm{m}$; magnification: $25 \times$ ). 


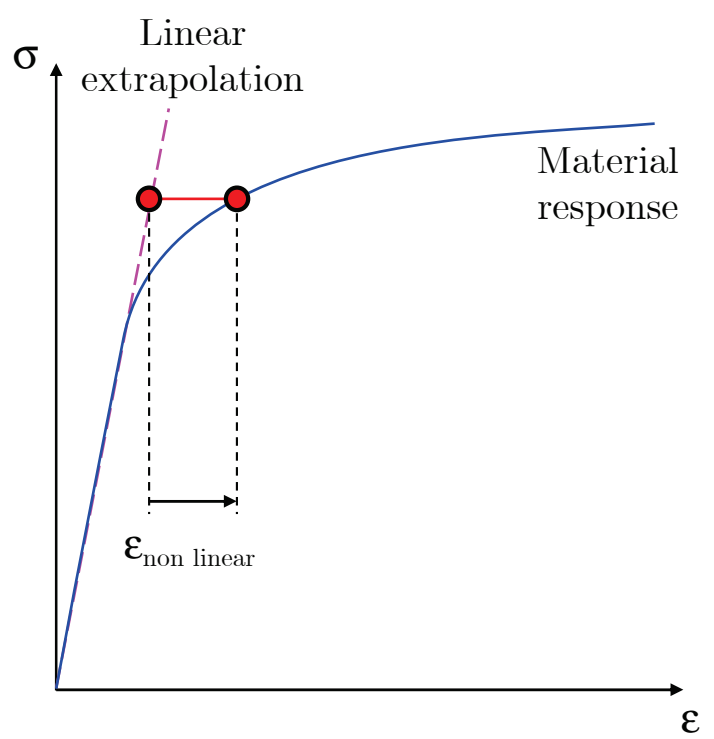

Figure 12: Principle of the calculation of $\varepsilon_{\text {non linear }}$ for a 1D stress/strain curve.

\subsection{Notion of representative elementary volume}

With the proposed method, it is also interesting to investigate experimentally the notion of representative elementary volume (REV). Indeed, the concept of REV is essential to determine, through homogenization schemes, the mechanical properties of a bulk material. But, in practice, the size of the REV is often chosen more or less arbitrarily from statistical considerations. In this context, an experimental answer to this important question would be of a great interest.

As a first step towards this goal, the $\varepsilon_{x x}$ strain maps have been segmented in 4 and in 16 . Then, the average strains over the corresponding subregions have been calculated and compared to the average strain over the whole strain map. This approach will give an estimate of the size of the REV regarding the mean value of the strain. Obviously, an implicit hypothesis of representability within the thickness of the sample is made (as the computed maps only give access to 2D surface and not bulk information).

The sizes of the subregions for the splitting in 4 and in 16 are respectively $225 \times 170 \mu \mathrm{m}^{2}$ and $113 \times 85 \mu \mathrm{m}^{2}$ (for a typical grain size of around $40 / 50 \mu \mathrm{m}$ ). The different stress/strain curves are shown in figures 14 and 15 .

It can be seen on these curves that, for the ones corresponding to the splitting in 4, the maximal difference between the global average strain and the average strain corresponding to a subregion corresponds to a difference of $7 \%$ which is still acceptable. But, for the curves corresponding to the splitting in 16, the maximal difference reaches $30 \%$ which allows to assert that the corresponding size of subregion is inferior to that of the REV.

From this first approach, it can be concluded that the size of the REV seems to be situated between the size of the whole field and its quarter. This issue should be investigated more precisely to be able to draw a definite conclusion. However and although this approach to determine the REV is not as relevant and thorough as the one that can be found in Hoc et al. [2003] (involving measurement of the orientations of the grains through a EBSD system), it remains a fast and easy way to give a first idea of the size of the REV once the full-field deformation data are available.

\subsection{Problem faced: gratings cracking}

During the tensile test, cracks on the photoresist appeared as early as for a global longitudinal strain of about $1 \%$. At first, these very small cracks do not disturb the measurements. But at around $1.3 \%$ of global longitudinal strain, these cracks begin to deteriorate the phase maps and thus the displacement ones.

Beyond $1.5 \%$ of average longitudinal strain, the cracks are so influent that it is not possible to ensure a relevant measurement anymore (Fig. 16). This is quite restrictive as practically the range where strains can be studied is between $10^{-3}$ (for resolution considerations) and $1.5 \times 10^{-2}$. Two main solutions to this problem have been envisaged: 


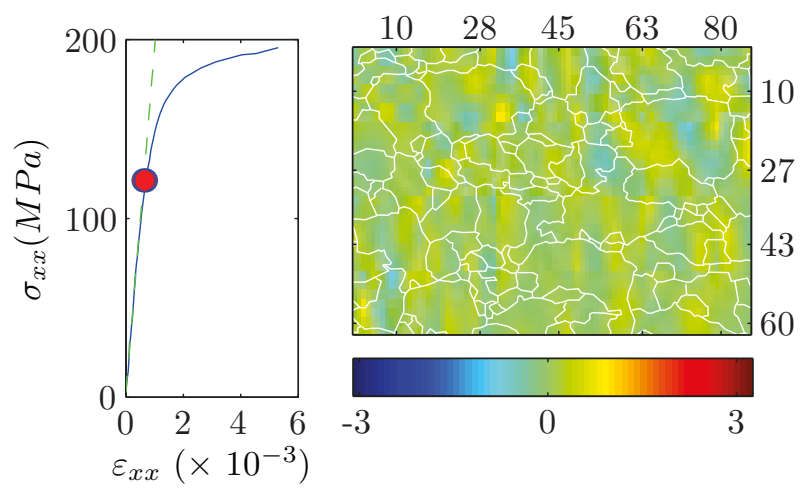

(a) Step 1
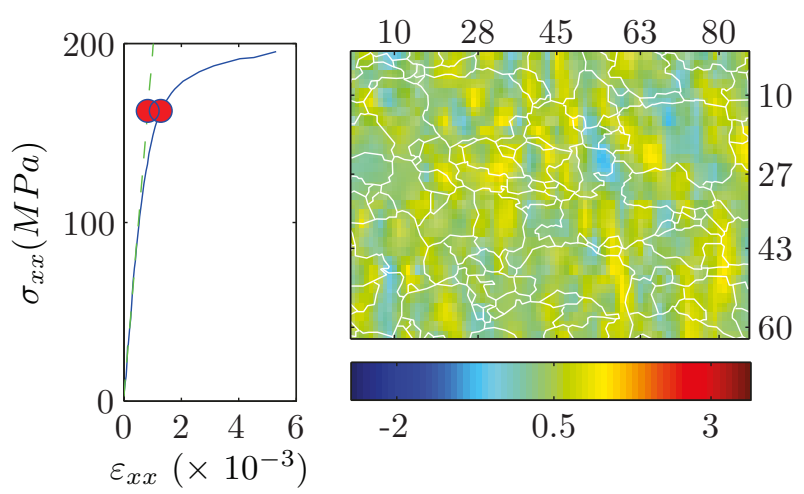

(c) Step 3


(e) Step 5
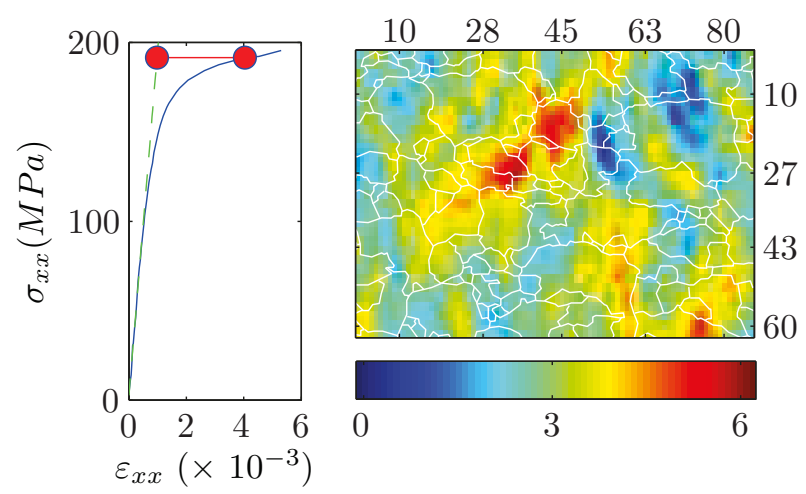

(g) Step 7
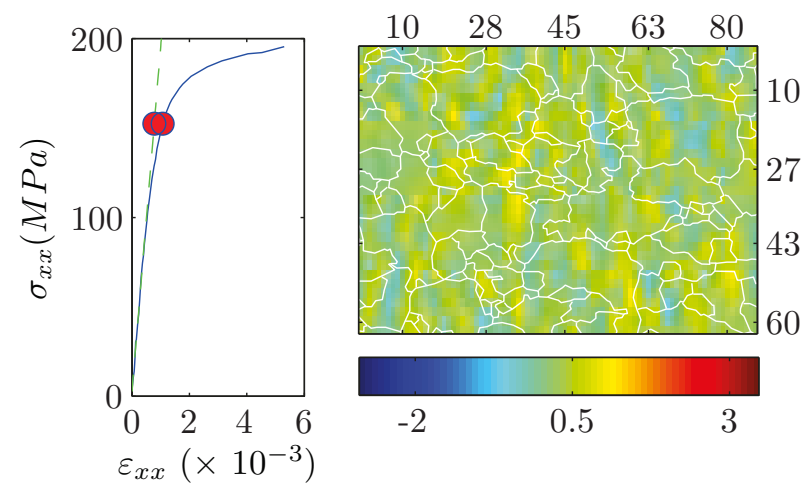

(b) Step 2


(d) Step 4


(f) Step 6
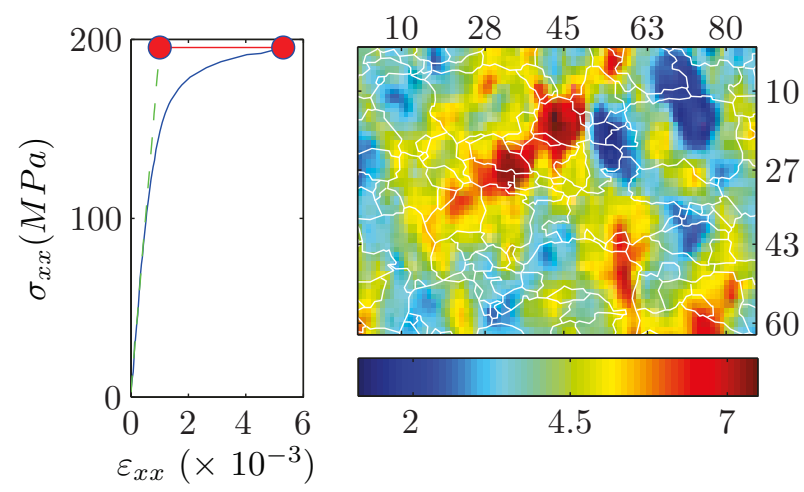

(h) Step 8

Figure 13: Non-linear strain maps of $\varepsilon_{x x}$ for a tensile test on the ferritic steel specimen with a $2 \times 2$ stitching (grating pitch: $5.6 \mu$ m; magnification: $25 \times)$. 


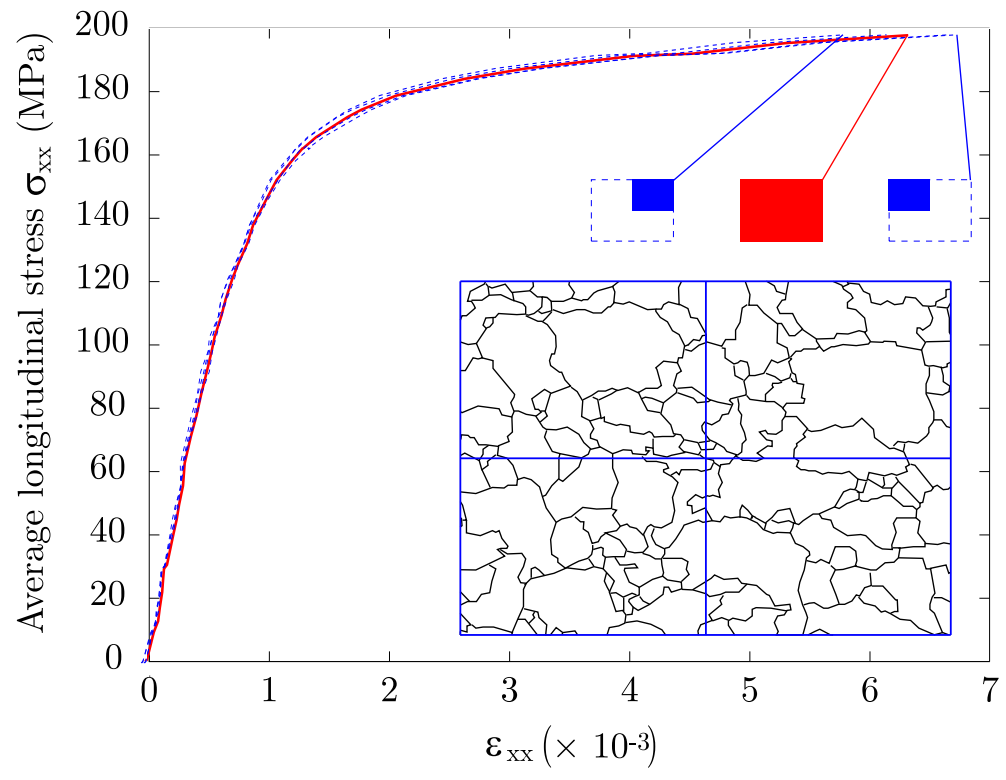

Figure 14: Average stress/strain curves for a sub-region size of $225 \times 170 \mu \mathrm{m}^{2}$.

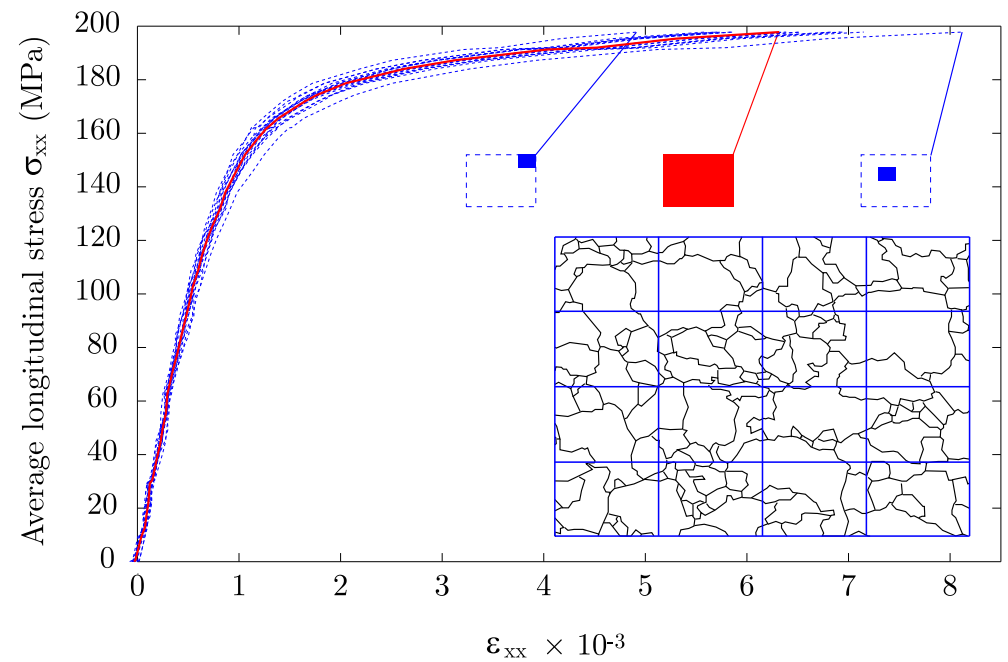

Figure 15: Average stress/strain curves for a sub-region size of $113 \times 85 \mu \mathrm{m}^{2}$. 
- the use of a less brittle photoresist (or the use of the same one but with a reduced temperature for the curing performed before its exposure to remove the solvent; a lower temperature should result in a lower brittleness);

- the use of etched gratings: direct "printing" of the pattern onto the material under study.

Both solutions are presently under evaluation.

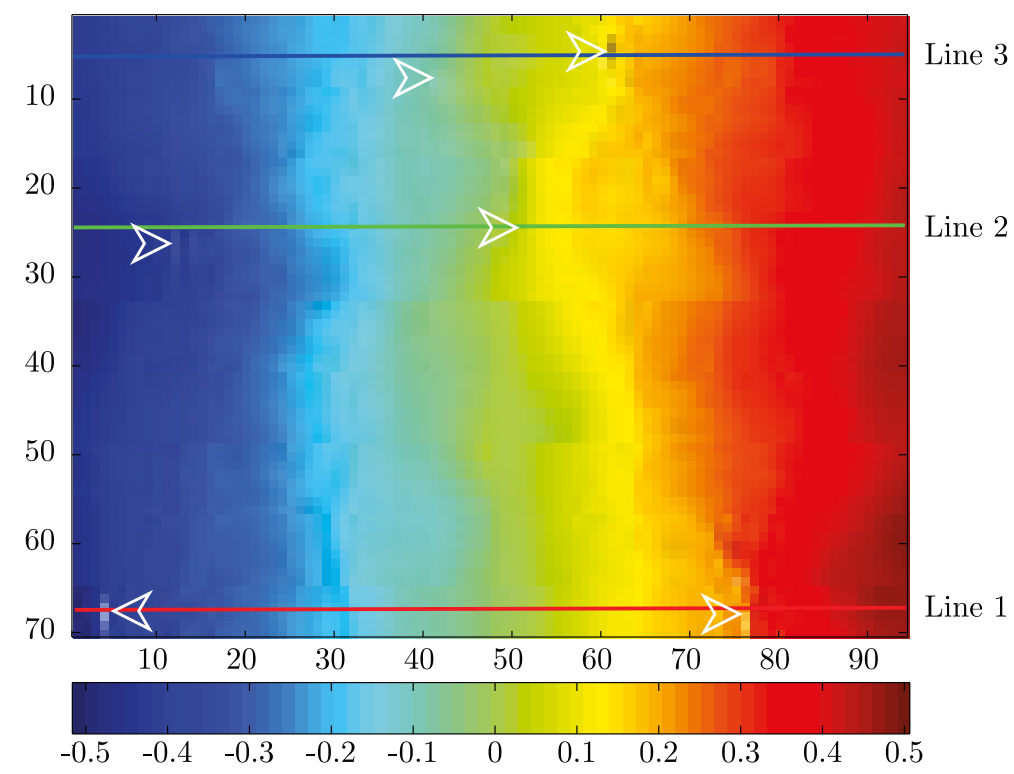

(a) $u_{x}$ map

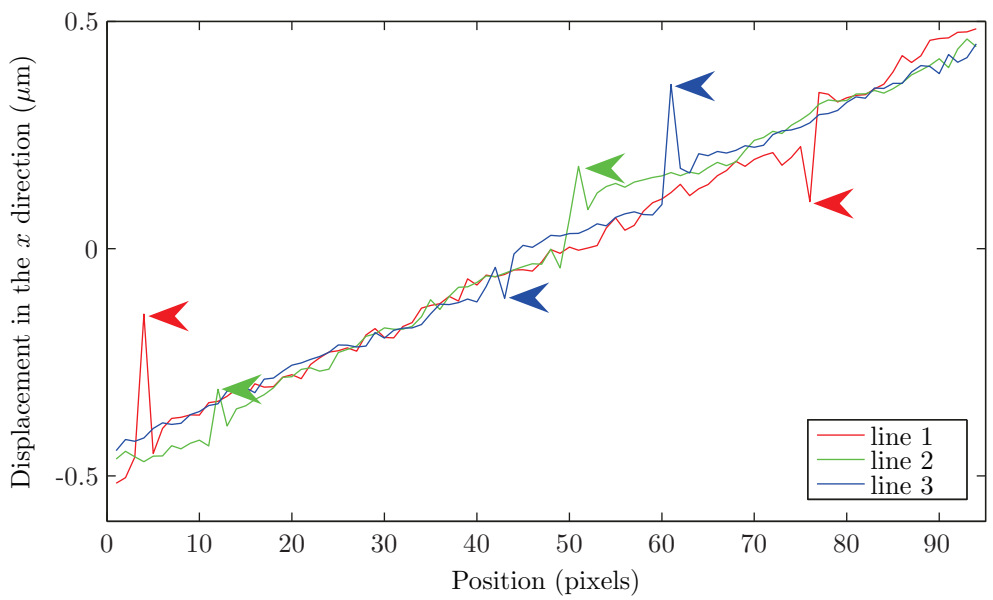

(b) Extracted profiles

Figure 16: Incremental $u_{x}$ map corresponding to a global strain value $\varepsilon_{x x}$ of $1.5 \%$ and extracted profile.

\section{Conclusion}

In this paper, full-field strain measurements at the microscale were performed on a ferritic steel specimen. After having recalled the bases of the developed and implemented full-field strain measurement method, its performances have been quantified. The experimental procedure has been precisely described including the particular attention paid to the reduction of rigid body motions, the way the mechanical results can be correlated to the microstructure and 
how the field of view can be increased through the development of an adapted image stitching algorithm. Finally, the mechanical test has underlined the ability of the proposed method to detect the onset of strain localization in the material. It has also been shown that with such a full-field method, it is possible, and would be very useful for the scientific community, to experimentally determine the size of the representative elementary volume (REV). The paper is concluded by some considerations on the limitations of the current approach due to the cracking of the gratings beyond $1 \%$ of global longitudinal strain and on a possible alternative solution that still needs improvements before being applied.

Compared to the existing techniques in the literature, the present one is dedicated to the measurement of small localized strains. It contains two main novelties. The first one is the use of the grid method with spatial phase shifting at this scale. This enables to reach a better resolution vs spatial resolution compromise than for digital image correlation techniques, for instance. The second and main novelty is the use of a white light interferometric microscope to digitize the measurement signal. The main advantage over usual white light microscopy is the fact that the problem of small depth-of-field is no longer an issue. This is a very important practical point. The main advantage over SEM measurements is that it is easier to use and more space is available to fit a testing machine. Obviously, the main limitations concern the spatial resolution limited to about $1 \mu \mathrm{m}$ by the average wavelength of white light, the cracking of the photoresist after a global longitudinal strain superior to $1.5 \%$ and the fact that the pattern is hiding the microstructure that cannot be observed during the mechanical test. It must be emphasized that for applications requiring larger strains or for specimens difficult to coat (biomaterials), the surface roughness signal itself could be used together with a correlation algorithm to produce displacement maps. This constitutes an important possible extension of the present method.

\section{Acknowledgement}

This research was conducted within the framework of the "NANODEF" project financially supported by the French Ministry for Research and the Champagne-Ardenne Regional Council.

\section{References}

L. Allais, M. Bornert, T. Bretheau, and D. Caldemaison. "Experimental characterization of the local strain field in a heterogeneous elastoplastic material". Acta Metallurgica et Materialia, 42, N11:3865-3880, 1994.

S. Avril and F. Pierron. "General framework for the identification of elastic constitutive parameters from full-field measurements". International Journal of Solids and Structures, 44:4978-5002, 2007.

S. Avril, P. Feissel, F. Pierron, and P. Villon. "estimation of the strain field from full-field displacement noisy data: comparing finite elements global least squares and polynomial diffuse approximation". European Journal of Computational Mechanics, 2008. accepted.

C. Bonavolontà, M. Valentino, M. Adamo, and E. Sarnelli. "Detection of plastic deformation in structural steel using scanning SQUID microscopy". Measurement Science and Technology, 18:2116-2120, 2007.

J. Bulhak and Y. Surrel. Mesure de déplacements et de déformations : quelle résolution spatiale ? In Photomécanique 2001, Étude du comportement des matériaux et des structures, 2001.

W. Cleveland and C. Loader. Smoothing by local regression: principles and methods. In W. Haerdle and M. G. Schimek, editors, Statistical Theory and Computational Aspects of Smoothing, pages 10-49. Springer, 1996.

J.W. Dally and D.T. Read. "Electron beam moiré". Experimental Mechanics, 33:270-277, 1993.

A. El Bartali, V. Aubin, and S. Degallaix. "Fatigue damage analysis in a duplex stainless steel by digital image correlation technique". Fatigue and Fracture in Engineering Materials and Structures, 31:137-151, 2008.

Z. Guo, H. Xie, B. Liu, Dain F., P. Chen, Q. Zhang, and F. Huang. "Study on deformation of polycrystalline aluminum alloy using moiré interferometry". Experimental Mechanics, 46:699-711, 2006.

E. Héripré, M. Dexet, J. Crépin, L. Gélébart, A. Roos, M. Bornert, and D. Caldemaison. "Coupling between experimental measurements and polycrystal finite element calculations for micromechanical study of metallic materials". International Journal of Plasticity, 23:1512-1539, 2007.

T. Hoc, J. Crépin, L. Gélébart, and A. Zaoui. "A procedure for identifying the plastic behavior of single crystals from the local response of polycrystals". Acta Materiallia, 51:5477-5488, 2003.

J. Kang, Y. Osiskov, J.D. Embury, and D.S. Wilkinson. "Digital image correlation studies for microscopic strain distribution and damage in dual phase steels". Scripta Materialia, 56:999-1002, 2007.

F. Lagattu, F. Bridier, P. Villechaise, and J. Brillaud. "In-plane strain measurements on a microscopic scale by coupling digital image correlation and an in situ SEM technique”. Materials Charaterization, 56:10-18, 2006.

F. Maquin and F. Pierron. "Heat dissipation measurements in low stress cyclic loading of metallic materials: from internal friction to microplasticity". Mechanics of Materials, 41:928-942, 2009.

R. Moulart, S. Avril, and F. Pierron. "Identification of the through-thickness rigidities of a thick laminated composite tube". Composites Part A: Applied Science and Manufacturing, 37:326-336, 2006. 
R. Moulart, R. Rotinat, F. Pierron, and G. Lerondel. "On the realization of microscopic grids for local strain measurement by direct interferometric photolithography". Optics and Lasers in Engineering, 45:1131-1147, 2007.

B. Nayroles, G. Touzot, and P. Villon. "Generalizing the finite element method: Diffuse approximation and diffuse elements". Computational Mechanics, 10:307-318, 1992

G. Nicoletto. "On the visualization of heterogeneous plastic strains by Moiré interferometry". Optics and Lasers in Engineering, 37:433-442, 2002.

F. Pierron, B. Green, and M.R. Wisnom. "Full-field assessment of the damage process of laminated composite open-hole tensile specimens. Part I: Methodology". Composites Part A: Applied Science and Manufacturing, 38(11):2307-2320, 2007a.

F. Pierron, B. Green, M.R. Wisnom, and S. Hallett. Full-field assessment of the damage process of laminated composite open-hole tensile specimens. Part II: Experimental results. Composites Part A: Applied Science and Manufacturing, 38(11):2321-2332, 2007b.

B.M. Schroeter and D.L. McDowell. "Measurement of deformation fields in polycrystalline OFHC copper". International Journal of Platicity, 19: 1355-1376, 2003

Y. Surrel. "Moiré and grid methods: a signal-processing approach”. In R.J. Pryputniewicz and J. Stupnicki, editors, Interferometry '94 : Photomechanics, volume SPIE 2342, 1994.

Y. Surrel. "Design of algorithms for phase measurements by the use of phase-stepping". Applied Optics, 35:51-60, 1996.

Y. Surrel. "Fringe analysis". In P.K. Rastogi, editor, Photomechanics, 2000.

J.C. Wyant. "White light interferometry". In H.J. Caulfield, editor, Holography: A Tribute to Yuri Denisyuk and Emmett Leith, volume SPIE 4737, 2002

H. Xie, B. Li, R. Geer, B. Xu, and J. Castracane. "Focused ion beam moiré method". Optics and Lasers in Engineering, 40:163-177, 2003. 